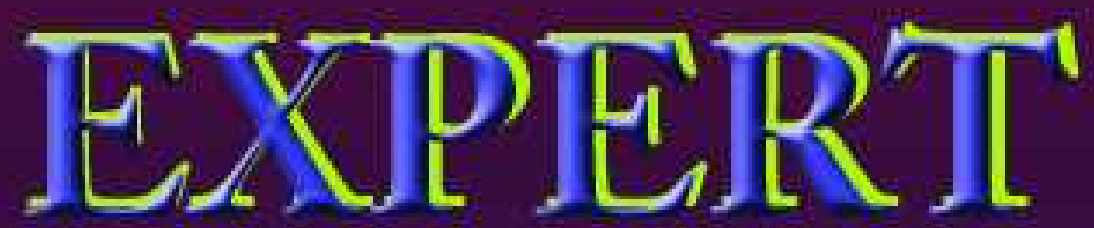

Jurnal Sistem Informasi

PERANCANGAN PROTOTYPE TEKNOLOGI SMART BUILDING MENGGUNAKAN ARDUINO BERBASIS WEB SERVER UNTUK MENDUKUNG PEMBANGUNAN PROPINSI LAMPUNG MENUJU PROGRAM LAMPUNG "SMART CITY"

Budi Usmanto, Tri Susilowati

SISTEM PENDUKUNG KEPUTUSAN PERANGKINGAN SEKOLAH MENENGAH KEJURUAN (SMK) DI KABUPATEN PRINGSEWU MENGGUNAKAN METODE WEIGHTED PRODUCT (WP)

Oktafianto, Elisabet Yunacti Anggracni, Suyono

OTORISASI PENGGUNA LABORATORIUM IBI DARMAJAYA BERBASIS CLIENT SERVER

Hendra Kurniawan, Hermanto

SISTEM PENDUKUNG KEPUTUSAN BERBASIS ANALYTICAL HIERARKHI PROCESS UNTUK PENENTUAN PENGISIAN JABATAN

Fenty Ariani

SEBARAN MENARA TELEKOMUNIKASI SELULER BERSAMA BERBASIS GIS (GEOGRAPHIC INFORMATION SYSTEM)

DI WILAYAH KABUPATEN LAMPUNG TENGAH

Taqwan Thamrin, Wiwin Susanty

AUTHENTIFIKASI LOGIN USER PADA PERANGKAT LUNAK MENGGUNAKAN ARDUINO DAN ENKRIPSI AES 256

Apri Triansah

ISSN : 2088-5555

$$
\text { Write To Be Experte }
$$




\section{Expert}

Jurnal Manajemen Sistem Informasi dan Teknologi

Volume 07, Nomor 02, Desember 2017

\begin{tabular}{|c|c|}
\hline Judul & Hal \\
\hline $\begin{array}{lllr}\text { PERANCANGAN } & \text { PROTOTYPE } & \text { TEKNOLOGI } & \text { SMART } \\
\text { BUILDING } & \text { MENGGUNAKAN ARDUINO BERBASIS WEB } \\
\text { SERVER } & \text { UNTUK } & \text { MENDUKUNG PEMBANGUNAN } \\
\text { PROPINSI LAMPUNG MENUJU PROGRAM LAMPUNG } \\
\text { "SMART CITY" }\end{array}$ & $57-65$ \\
\hline $\begin{array}{l}\text { SISTEM PENDUKUNG KEPUTUSAN PERANGKINGAN } \\
\text { SEKOLAH MENENGAH KEJURUAN (SMK) DI KABUPATEN } \\
\text { PRINGSEWU MENGGUNAKAN METODE WEIGHTED } \\
\text { PRODUCT (WP) }\end{array}$ & $66-71$ \\
\hline $\begin{array}{l}\text { OTORISASI } \quad \text { PENGGUNA } \quad \text { LABORATORIUM } \\
\text { DARMAJAYA BERBASIS CLIENT SERVER }\end{array}$ & $72-76$ \\
\hline $\begin{array}{l}\text { SISTEM PENDUKUNG KEPUTUSAN } \quad \text { BERBASIS } \\
\text { ANALYTICAL HIERARKHI PROCESS UNTUK PENENTUAN } \\
\text { PENGISIAN JABATAN }\end{array}$ & $77-82$ \\
\hline $\begin{array}{l}\text { SEBARAN MENARA TELEKOMUNIKASI SELULER } \\
\text { BERSAMA BERBASIS GIS (GEOGRAPHIC INFORMATION } \\
\text { SYSTEM) DI WILAYAH KABUPATEN LAMPUNG TENGAH }\end{array}$ & $83-89$ \\
\hline $\begin{array}{l}\text { AUTHENTIFIKASI LOGIN USER PADA PERANGKAT } \\
\text { LUNAK MENGGUNAKAN ARDUINO DAN ENKRIPSI AES } \\
256\end{array}$ & $90-95$ \\
\hline
\end{tabular}

Fakultas Ilmu Komputer

Universitas Bandar Lampung

\begin{tabular}{|c|c|c|c|c|}
\hline \multirow{2}{*}{ JMSIT } & Volume 07 & Nomor 02 & Lampung, Desember & ISSN \\
& & 2017 & $2088-5555$ \\
\hline
\end{tabular}




\section{TIM PENYUNTING}

\section{Penanggung Jawab}

Ahmad Cucus, S.Kom., M.Kom.

Ketua Tim Redaksi:

Taqwan Thamrin, ST, M.Sc.

Penyunting Ahli (Mitra Bestari):

Mustofa Usman, Ph.D (Universitas Lampung)

Dra. Wamiliana, MA., Ph.D (Universitas Lampung)

Iing Lukman, M.Sc., Ph. D (Universitas Malahayati)

\section{Penyunting:}

Fenty Ariani, S.Kom, M.Kom

Robby Yuli Endra, S.Kom.,M.Kom

Ayu Kartika Puspa, S.Kom, M.TI

Erlangga, S.Kom, M.Kom

\section{Pelaksana Teknis:}

Dian Resha Agustina, S.Kom

\section{Alamat Penerbit/Redaksi:}

Pusat Studi Teknologi Informasi

Fakultas Ilmu Komputer

Universitas Bandar Lampung

Gedung Business Center Lt.2

Jl. Zainal Abidin Pagar Alam No. 26

Bandar Lampung

Email: Journal.expert@ubl.ac.id 


\title{
PERANCANGAN PROTOTYPE TEKNOLOGI SMART BUILDING MENGGUNAKAN ARDUINO BERBASIS WEB SERVER UNTUK MENDUKUNG PEMBANGUNAN PROPINSI LAMPUNG MENUJU PROGRAM LAMPUNG "SMART CITY"
}

\author{
Budi Usmanto $^{\# 1}$, Tri Susilowati $^{* 2}$ \\ \#1*2 Program Studi Sistem Informasi \\ STMIK Pringsewu, Lampung \\ Jln Wismarini No.09 Pringsewu, Lampung telp/fax (0729) 22240 \\ ${ }^{1}$ budiusmanto@gmail. com \\ ${ }^{2}$ trisusilowati423@gmail.com
}

\begin{abstract}
Abstrak
Sistem Smart Building adalah sistem aplikasi yang merupakan gabungan antara teknologi dan pelayanan yang dikhususkan pada lingkungan rumah atau gedung dengan fungsi tertentu yang bertujuan meningkatkan efisiensi, kenyamanan dan keamanan penghuninya. Berdasarkan hal tersebut pada penelitian ini dirancang dan dibuat prototype sistem otomasi pada gedung berbasis arduino web server. Sistem ini berfungsi untuk memantau suhu, kelembapan, deteksi tegangan dan arus listrik, deteksi kebakaran, deteksi intensitas hujan, deteksi asap, deteksi gempa, deteksi banjir, dan deteksi pergerakan jika ada orang yang menyusup ke dalam rumah maupun gedung. Alat ini juga terintegrasi dengan perangkat-perangkat listrik yang digunakan untuk memantau serta mengontrol lampu yang dihubungkan dengan sebuah relay, dan menggerakan servo yang berfungsi sebagai alat pembukan dan penutup pagar. Arduino Web Server terdiri dari gabungan antara arduino uno dan Ethernet shield, bertindak sebagai sebuah embedded web server yang berfungsi sebagai pemantau sekaligus pengontrol sistem secara keseluruhan. Sistem ini secara keseluruhan dapat diakses kapan saja dan dimana saja melalui komputer dan smartphone secara realtime dengan menggunakan browser. Sistem ini juga akan memberikan informasi terbaru secara realtime jika terjadi hal-hal yang tidak diinginkan melalui Twitter dan Facebook.
\end{abstract}

Kata kunci : Smart Building, Smart City, Web Server, Arduino

\section{PENDAHULUAN}

\subsection{Latar Belakang Masalah}

Dalam kebijakan nasional yang tertuang dalam PP 26 tahun 2008 tentang Rencana Tata Ruang Wilayah Nasional, Provinsi Lampung ditetapkan sebagai Pusat Kegiatan Nasional dan sebagai salah satu kawasan andalan nasional yang ada di Sumatera, dibidang transportasi terutama di Kota Bandarlampung berkembang menjadi kota cerdas (smart city).

Kourtit \& Nijkamp (2012) mengungkapkan bahwa Smart City telah menjadi landmark dalam perencanaan kota. Smart City merupakan hasil dari pengembangan pengetahuan yang intensif dan strategi kreatif dalam peningkatan kualitas sosialekonomi, ekologi, daya kompetitif kota. Kemunculan Smart City merupakan hasil dari gabungan modal sumberdaya manusia (contohnya angkatan kerja terdidik), modal infrastruktur (contohnya fasilitas komunikasi yang berteknologi tinggi), modal sosial (contohnya jaringan komunitas yang terbuka) dan modal entrepreuneurial (contohnya aktifitas bisnis kreatif). Pemerintahan yang kuat dan dapat dipercaya disertai dengan orang-orang yang kreatif dan berpikiran terbuka akan meningkatkan produktifitas lokal dan mempercepat pertumbuhan ekonomi suatu kota. Komponen-komponen penting dalam konsep Smart City ini meliputi 3 komponen yaitu: teknologi (hard infrastructure maupun soft infrastructure), manusia (kreatifitas, pendidikan), dan institusi (pemerintahan dan kebijakan) (Nam \& Pardo, 2011). Hubungan dari ketiga faktor ini dapat menciptakan Smart City, yaitu ketika investasi pada modal manusia/sosial dan infrastruktur dengan teknologi informasi dan komunikasi dapat mendorong pembangunan berkelanjutan dan meningkatkan kualitas hidup masyarakatnya dengan disertai pemerintahan yang partisipatif.

Kehidupan dengan kualitas hidup yang tinggi adalah dambaan semua orang, dengan kemajuan teknologi manusia berharap untuk hidup lebih mudah, aman, nyaman dan juga hemat energi. Namun timbul beberapa pertanyaan dari tujuan diatas, pertanyaan pertama adalah apa itu hidup yang mudah, aman, nyaman dan hemat energi? Bagaimana cara mendapatkan hidup mudah, aman, nyaman, dan juga hemat energi ditengah gejolak pertumbuhan penduduk di kota yang terus meningkat. Dengan kenyataan mayoritas orang hidup dikota, maka kualitas hidup yang mencerminkan hidup yang 
mudah, aman dan nyaman menjadi suatu impian masyarakat kota. Namun dengan banyaknya penduduk, bentukan kota dan tingkat kepadatan yang tinggi menjadi suatu hambatan untuk mencapai kualitas hidup tersebut. Tingkat kriminalitas yang tinggi, mobilitas yang tinggi, transportasi yang padat tidak di dukung dengan saran prasarana yang memadai dan masih banyak permasalahanpermasalahan lainnya. Untuk menjawab keinginan manusia akan kualitas hidup yang mudah aman dan nyaman maka muncul berbagai metoda dan strategi untuk mencapai hal tersebut, salah satu metoda tersebut adalah konsep perencanaan kota cerdas atau biasa disebut smart city.

Selain itu, mengingat saat ini kebutuhan manusia akan energi listrik sangat tinggi. Boleh dikatakan tanpa listrik kita tidak bisa hidup dengan nyaman. Hampir seluruh peralatan rumah tangga memerlukan listrik. Mulai dari TV, komputer, pompa air, rice cooker, dan alat rumah tangga lainnya. Namun saat ini energi listrik terbilang mahal terlebih dengan adanya global warming yang mengancam kehidupan manusia. Dengan menerapkan teknologi smart home dapat mengefisiensikan pemakaian listrik di rumah, karena pada sistem smart home penggunaan listrik akan diatur sedemikian rupa sehingga meningkatkan efisiensi penggunaan listrik.

\subsection{Rumusan Masalah}

Dengan melihat latar belakang di atas, maka rumusan masalah dalam penelitian ini adalah:

1. Bagaimana merancang dan membuat teknologi smart building yang dapat mengkontrol aktifitas dalam gedung secara otomatis?

2. Bagaimana merancang dan membuat teknologi smart building yang dapat mengkontrol aktifitas dalam gedung yang dapat diakses melalui halaman web?

3. Bagaimana rancangan sistem untuk dapat memberikan informasi-informasi yang terbaca dari sensor-sensor yang tertanam melaui halaman web yang dapat diakses kapan saja dan dimana saja secara realtime?

4. Bagaimana rancangan sistem untuk dapat melakukan updating secara melalui Twitter dan Facebook?

5. Bagaimana sistem dan produk yang dihasilkan dapat memberikan sumbangsih untuk pengembangan dan inovasi dalam perancangan teknologi smart untuk mendukung program smart city di Provinsi Lampung?

\subsection{Tujuan Penelitian}

Tujuan dari penelitian secara umum adalah dihasilkannya suatu produk dan sistem teknologi smart building untuk meningkatkan efisiensi, kenyamanan dan keamanan penggunanya serta memberikan kontribusi berupa hasil produk yang dapat dikembangan untuk membangun smart city.

Tujuan dari penelitian secara khusus adalah Untuk membuat perancangan dan implementasi pemanfaatan teknologi untuk membuat smart city atau salah satu contohnya smart building, sebagai akses informasi dari sistem smart city melalui sistem smart building, untuk mengetahui setiap saat kejadian yang terjadi di dalam rumah dan diharapkan dapat menghasilkan suatu rumah yang nyaman dan aman, dan sebagai upaya terobosan dalam melakukan efisiensi penggunaan energi, dan deteksi bahaya dengan memanfaatkan fitur kontrol dan otomatisasi sistem dalam rumah.

\subsection{Manfaat Penelitian} antara lain:

Manfaat yang diharapkan dari penelitian ini

1. Dihasilkannya suatu prototype untuk produk Smart Building berbasis web server.

2. Dapat meningkatkan efisiensi penggunaan listrik dalam gedung, karena sistem dapat dikontrol jarak jauh dengan menggunakan browser.

3. Memberikan kontribusi dan gagasan berupa pengetahuan, pengembangan untuk menciptakan sistem monitoring dan kendali sistem jarak jauh dengan smart technology menggunakan jaringan internet berbasis arduino dan web server, sehingga dapat dimanfaatkan oleh masyarakat untuk memonitoring kondisi gedung maupun rumahnya dengan menggunakan browser.

4. Dapat diintegrasikan dengan smart city untuk pemantauan monitoring dan mendapatkan informasi tentang kondisi gedung, kantor maupun rumah jika terjadi bencana dari jarak jauh.

5. Dapat memberikan pengembangan bagi dosen untuk implementasi teori-teori yang didapat dengan mengimpelementasikannya ke dalam suatu produk industry.

\section{TINJAUAN PUSTAKA DAN LANDASAN TEORI}

\subsection{Penelitian Terdahulu}

Penelitian tentang Analisis Penerapan Smart City dan Internet of Things (IoT) di Indonesia pernah dilakukan oleh (Syahbudin). Penelitian ini merupakan konsep yang mengetengahkan sebuah tatanan kota cerdas yang bisa berperan dalam memudahkan masyarakat untuk mendapatkan informasi secara cepat dan tepat. Menurutnya penggunaan teknologi 
dengan konsep Internet of Things (IoT) adalah salah satu solusi terbaik dalam hal infrastruktur smart city.

Penelitian tentang Perancangan Prototype Web-Based Online Smart Home Controlled by Smartphone pernah dilakukan oleh (Arifiyanto, dkk). Sistem ini terdiri dari sistem pengontrolan dan kemanan. Aplikasinya terdiri dari main program yang terletak di komputer server, sekaligus web server. Aplikasi yang terdapat di komputer server terhubung secara serial dengan mikrokontroller ATMEGA 8535 untuk mengatur kondisi lampu. Tidak hanya lampu, garasi, gerbang depan, lemari es, pompa air, dan semua peralatan yang menyala menggunakan sistem on/off juga bisa diatur dengan aplikasi ini.

Dari penelitian yang pernah dilakukan, belum pernah ada yang menerapkan Prototype Teknologi Smart Building Menggunakan Arduino Berbasis Web Server untuk Mendukung Pembangunan Propinsi Lampung Menuju Program Lampung Smart City. Berbeda dengan penelitian-penelitian yang pernah dilakukan sebelumnya penelitian ini mengggunakan Ethernet Shield dan Arduino sebagai kontrol dan sekaligus servernya. Keuntungan sistem ini dibandingkan sistem sebelumnya antara lain penggunaan daya listrik yang lebih kecil yaitu berkisar 5 watt, hal ini tentunya berbeda jika dengan menggunakan komputer sebagai server yang bisa mengkonsumsi listrik sampai dengan 450 watt. Keuntungan lainnya karena kontrol dan server pada satu alat, sehingga pembacaan sensor-sensor dan kontrol lebih sesuai dengan kondisi yang sebenarnya, berbeda jika kontrol menggunakan sistem dan server yang berbeda, perlu adanya komunikasi dua arah untuk melihat kondisi di sistem kontrol dan servernya. Penelitian ini menghasilkan suatu produk yang dapat digunakan untuk memantau suhu, kelembapan, deteksi tegangan dan arus listrik, deteksi kebakaran, deteksi intensitas hujan, deteksi asap, deteksi gempa, deteksi banjir, dan deteksi pergerakan jika ada orang yang menyusup ke dalam rumah maupun gedung. Alat ini juga terintegrasi dengan perangkat-perangkat listrik yang digunakan untuk memantau serta mengontrol lampu yang dihubungkan dengan sebuah relay, dan menggerakan servo yang berfungsi sebagai alat pembukan dan penutup pagar. Produk yang dihasilkan dapat dikembangkan lagi untuk membangun suatu prototype sistem dengan konsep smart city.

\subsection{Smart City}

Smart City atau secara harafiah berarti kota pintar, merupakan suatu konsep pengembangan dan implementasi teknologi yang diterapkan dalam suatu wilayah sebagai sebuah interaksi yang kompleks di antara berbagai sistem didalamnya. Dengan memanfaatkan teknologi informasi dan komunikasi yang dikemas dalam bentuk smart city dapat memberi dampak positif bagi beberapa aspek penting dalam kota seperti pemerintahan, kehidupan sosial masyarakat, transportasi, kualitas hidup, persaingan yang sehat di segala bidang. Beberapa contoh hal yang dapat diimplementasikan smart city dan green computing:

1. Pengembangan dan pemanfaatan arsitektur jaringan komputer yang lama tanpa harus menggantinya dengan menggunakan sistem yang ada sebanding dengan peralatan terbaru.

2. Berefisien dalam penggunaan energi dan juga dapat membuat sebuah sumber energi baru bagi kelangsungan kota tersebut.

3. Peningkatan mutu pendidikan dengan basis teknologi seperti e-learning.

4. Transportasi yang ramah lingkungan, menggunakan energi terbarukan, serta pengelolaan yang baik.

5. Layanan kesehatan masyarakat secara online dan mobile memanfaatkan mobile programming, jaringan komputer, cloud computing dan juga green computing dimana penggunaan kertas sebagai hasil cek-up atau registrasi bisa dikurangi.

Terdapat 6 jenis pembagian Smartcity:

1. Smart Economy

Smart Economy ditujukan untuk membuat inovasi dan kemampuan daya saing yang berguna untuk mencapai peningkatan ekonomi wilayah tersebut.

2. Smart Living

Pada Smart Living terdapat syarat, kriteria, dan tujuan untuk proses pengelolaan kualitas hidup dan budaya yang lebih baik dan pintar. Untuk mewujudkan smart living, terdapat tiga buah subbagian yang harus dipenuhi. Ketiga sub bagian tersebut adalah Education Facilities, Touristic Atractivity, dan ICT Infrastructure.

3. Smart People

Dengan adanya smart people, diharapkan dapat tercipta komunitas masyarakat yang smart. Hal ini ditujukan agar adanya partisipasi masyarakat yang smart sehingga mampu mengetahui manfaat dan mengelola serta mengembangkan smart city.

4. Smart Governance

Smart Governance merupakan bagian pada smart city yang mengkhususkan pada tata kelola pemerintahan. Adanya kerja sama antara pemerintah dan masyarakat ini diharapkan dapat mewujudkan tata kelola dan jalannya pemerintahan yang bersih, jujur, adil, dan 
berdemokrasi serta kualitas dan kuantitas layanan publik yang lebih baik.

5. Smart Mobility

Smart Mobility merupakan bagian pada smart city yang mengkhususkan pada transportasi dan mobilitas masyarakat.Sistem smart yang berbasiskan teknologi informasi untuk mengatur transportasi, traffic, dan pariwisata.

\section{Smart Environment}

\subsection{Smart Building}

Smart home system adalah sebuah sistem berbantuan komputer yang akan memberikan segala kenyamanan, keselamatan, keamanan dan penghematan energi, yang berlangsung secara otomatis dan terprogram melalui komputer, pada gedung atau rumah tinggal anda. Hanya dengan melakukan hubungan jaringan internet, maka kita dapat mengatur buka-tutup tirai yang mengunakan motor, memindah pakaian ketempat tertutup secara otomatis jika terjadi hujan, mengatur penerangan di dalam atau luar rumah, mengetahui kondisi cuaca dan temperatur di dalam rumah maupun di luar rumah, mengawasi seluruh aktivitas yang terjadi di rumah. Dengan kata lain bisa diartikan bahwa kita dapat mengatur semua prasarana rumah atau kantor yang menggunakan sumberdaya listrik sebagai pembangkit kerjanya.

\subsection{Hardware}

\subsubsection{Arduino}

Menurut Djuandi (2011), Arduino merupakan sebuah platform physical computing yang bersifat open source. Arduino adalah kombinasi dari hardware, bahasa pemrograman dan integrated development environment (IDE). IDE merupakan software yang digunakan untuk menulis program, mengkompilasi menjadi kode biner dan meng-upload ke dalam memori mikrokontroler.

Dalam bahasa pemograman Arduino terdapat tiga bagian utama, yaitu struktur, variable dan fungsi (Artanto, 2012). Bahasa Arduino ini mirip dengan bahasa C. Menurut Nugroho (2012), bahasa C mempunyai sifat portable yaitu dengan sedikit atau tanpa perubahan. Program yang ditulis dengan bahasa ini dapat dijalankan pada komputer lainnya. Keunggulan lainnya dari bahasa $\mathrm{C}$ adalah prosesnya yang cepat. Program yang ditulis dengan bahasa $\mathrm{C}$ bila dijalankan kira-kira akan 50 kali lebih cepat dibandingkan dengan program yang ditulis dengan bahasa BASIC. Selain itu, program yang ditulis dengan bahasa $\mathrm{C}$ juga teratur dengan baik sehingga dokumentasi dapat dilakukan dengan baik. Dengan begitu modifikasi dan pengkoreksiaan terhadap program akan lebih mudah (Nugroho, 2012).

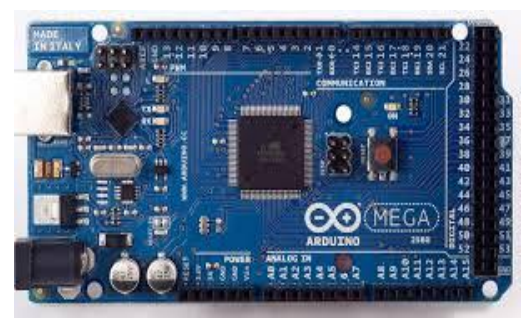

Gambar 1. Arduino Mega

\subsubsection{Ethernet Shield}

Ethernet Shield yang memungkinkan sebuah board Arduino untuk terhubung dengan internet. Shield ini dibuat berdasarkan ethernet chip Wiznet W5100. Wiznet W5100 menyediakan sebuah jaringan dengan kemampuan TCP dan UDP.

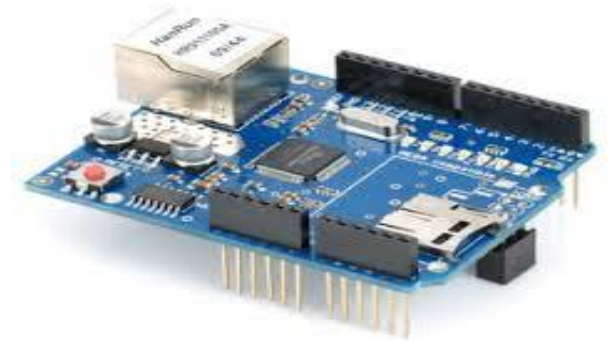

Gambar 2. Ethernet Shield

\subsubsection{Sensor}

Terdapat empat bagian utama dari sistem instrumentasi yaitu sensor, pengkondisian sinyal, pemrosesan data dan penampil. Agar pengambilan data dari sensor berjalan baik, perlu dilakukan pemilihan sensor yang tepat dengan kebutuhan. Setiap sensor memiliki kepekaan yang berbeda terhadap spektrum elektromagnetik dan dalam merekam objek terkecil yang masih dapat dikenali dan dibedakan terhadap objek lain atau lingkungan sekitarnya (resolusi special). Semakin kecil objek yang dapat direkam oleh sensor, semakin baik kualitas sensor tersebut. Sensor tersebut anatara lain adalah sensor suhu dan kelembaban (DHT11 temperature and humidity sensor), serta sensor cahaya (light dependent resistor), sensor gerak PIR, sensor hujan.

\subsubsection{IP Camera}

IP camera adalah jenis kamera video digital yang biasa digunakan untuk pemantauan keamanan dan dapat mengirim dan menerima data melalui jaringan komputer dan internet. Walaupun webcam juga dapat melakukan hal ini namun istilah " IP Camera" atau "Network Kamera" biasanya hanya digunakan untuk sistem pengawasan keamanan. IP 
Kamera pertama digunakan pertama kali pada tahun 1996.

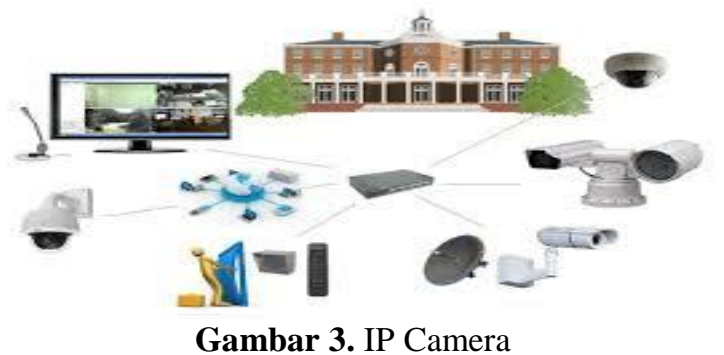

\subsection{Jaringan dan Tools}

\subsubsection{Definisi Jaringan Komputer}

Jaringan komputer merupakan gabungan antara teknologi komputer dan teknologi telekomunikasi.Gabungan teknologi ini melahirkan pengolahan data yang dapat didistribusikan, mencakup pemakaian database, software aplikasi dan peralatan hardwaresecara bersamaan, sehingga pengguna komputer yang sebelumnya hanya berdiri sendiri, kini telah diganti dengan sekumpulan komputer yang terpisah- pisah akan tetapi saling berhubungan dalam melaksanakan tugasnya, sistem seperti inilah disebut jaringan komputer (computernetwork).

\subsubsection{Model OSI layer dan Protocol (TCP/IP)}

Model referensi OSI terdiri atas lapisan berjumlah 7 buah (layer) yaitu : Physical, Data Link,Network,Transport, Session, Presentation, ApplicationSedangkan Protokol TCP/IP hanya memiliki empatlayer, yaitu: Aplication Layer, Hostto-host layer atau Transport layer, Internetworking layer atau internet layer, Network Interface layer atau Physical layer.

\subsubsection{IP address Public dan IP Address Private} IP address yang digunakan untuk keperluanLAN/intrenet disebut sebagai IP addressprivate. Sedangkan IP address yang digunakan untuk keperluan internet disebut IP addresspublic. Secara umum, IP address dapat dibagi menjadi 5 kelas, Kelas A, B, C, D, E. Namun dalam praktiknya hanya kelas $\mathrm{A}, \mathrm{B}$, dan $\mathrm{C}$ yang dipakai untuk keperluan umum. Ketiga kelas IP address ini disebut IP address unicast.IP address kelas D dan E digunakan untuk keperluan khusus. IP address kelas $\mathrm{D}$ disebut juga IP address multicast. Sedangkan IP address kelas E digunakan untuk keperluan riset.IP address (kelas A, B, dan C) dapat dipisahkan menjadi 2 bagian, yakni bagian network (bit-bit networks/networks bit) dan bagian host (bit-bit host/hostbits).

\subsubsection{Protokol OSPF}

OSPF dikembangkan menggunakan algoritma Dijkstra'sShortest Path First (SPF). Protokol Link State(LS) dapat mengetahui kondisi network secara lebih akurat. Masing-masing router memiliki gambaran jelas tentang topologi network, termasuk juga info bandwithdari network lainnya. Beberapa hal yang menjadi karakteristik LS yaitu dapat merespon dengan cepat terhadap perubahan network, mengirim update ketika terjadi perubahan pada network, mengirim update secara periodik pada interval tertentu, yang disebut dengan link state refresh.Untuk mengurangi perhitungan OSPF, maka protokol OSPF perlu mempartisi network menjadi beberapa area. Berikut ini ada beberapa area yang terkait dengan network OSPF yaitu backbone area, regular area, stub area, totally stuby area, NSSA dan totally NSSA.

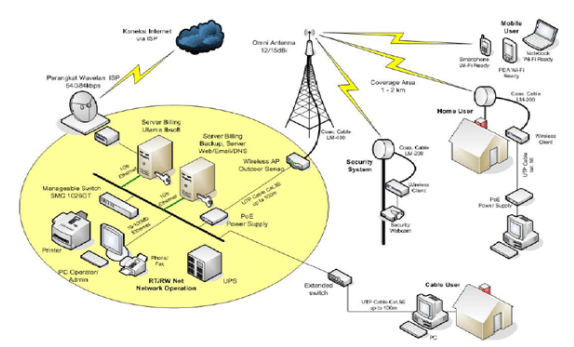

Gambar 4. Jaringan Internet

\subsection{HTTP Request Message}

Ketika web browser menjemput sebuah berkas dari web server, web browser menggunakan Hypertext Transfer Protocol (HTTP). HTTP adalah sebuah protokol request/respond, yang berarti computer mengirimkan sebuah permintaan (request) untuk berkas dan kemudian web server mengirim balik sebuah jawaban (respond).

Sebuah HTTP request message terdiri dari beberapa bagian yaitu: Request-line, Header, sebuah baris kosong, dan beberapa pesan opsional.

\subsection{Query string}

Dalam World Wide Web (WWW), sebuah query string adalah bagian dari Uniform Resource Locator (URL) yang mengandung data yang diteruskan kepada aplikasi web. Ketika sebuah halaman web diminta melalui HTTP, server akan mencari sebuah berkas pada kumpulan berkas yang berada dalam server tersebut berdasarkan URL yang diberikan. Berkas ini dapat berupa sebuah berkas biasa atau sebuah program.Penggunaan query string mengijinkan data yang dikirim dari HTTP client (biasanya berupa sebuah web browser) ke server. Berikut ini adalah contoh URL yang memiliki sebuah 
query string: http://server/path/program?query_string Ketika server menerima permintaan untuk halaman tersebut, server mungkin menjalankan sebuah program, meneruskan query_string tanpa terjadi perubahan ke program tersebut. Tanda Tanya digunakan sebagai pemisah dan bukan bagian dari query string. Jika URL yang diminta cocok dengan sebuah file bukan sebuah program maka seluruh query string akan diabaikan. Sebagai contoh ketika browser meminta halaman: http://server/utama.html?31231 maka server akan mengirimkan halaman utama.html dan mengabaikan apa saja yang mengikuti tanda tanya (?). Tetapi query string 31231 tersebut tetap diterima oleh server dan dapat digunakan untuk keperluan lain seperti untuk identifikasi atau sebuah perintah untuk server tergantung pada sistem yang berjalan pada server. Karena query string adalah bagian dari URL maka query string juga akan ada di HTTP request message.

\section{METODE PENELITIAN}

\subsection{Lokasi Penelitian}

Penelitian ini utamanya dilaksanakan pada Laboratorium STMIK Pringsewu. Selain itu, penelitian ini juga dilaksanakan di gedung maupun rumah untuk dilakukan studi lapangan.

\subsection{Alat dan Bahan}

Dalam mengerjakan penelitian ini mulai dari tahap observasi sampai tahap perancangan alat dan simulasi, penulis menggunakan perlengkapan komputer dan smartphone sebagai media untuk menjalankan program.

Arduino Web Server adalah gabungan antara arduino dan ethernet shield. Arduino berkomunikasi dengan ethernet shield menggunakan bus SPI. Komunikasi SPI ini diatur oleh library SPI.h dan Ethernet.h. Bus SPI pada arduino uno menggunakan pin digital 11, 12 dan 13. Konfigurasi bus SPI pada arduino untuk berkomunikasi dengan ethernet shield.

Arduino Web Server bertindak sebagai sebuah embedded web server, yang menyimpan halaman web sederhana yang menampilkan status peralatan yang terhubung dengan relay (lampu), status lingkungan rumah yang terhubung dengan sensorsensor di sekitar rumah.

Alat dan bahan untuk membuat system ini antara lain:

1. Komputer

2. Smartphone

3. Arduino web server

4. Relay

5. Sensor api

6. Sensor asap

7. Sensor gempa

8. Sensor suhu
9. Sensor kelembapan

10. Sensor arus dan tegangan

11. Sensor PIR

12. IP CAM

\subsection{Perancangan Sistem}

Langkah awal dalam perancangan sistem adalah analisis dan penentuan kebutuhan sistem. Pada langkah ini ditentukan kebutuhan apa saja yang harus dipenuhi oleh sistem. Secara garis besar, perangkat lunak yang dirancang adalah sebuah aplikasi web server. Aplikasi ini diharapkan dapat melakukan monitoring dan kontrol kerja sistem meliputi:

1. Menghidupkan dan memadamkan lampu dari server.

2. Melihat kondisi lampu.

3. Melakukan penjadwalan nyala lampu, dan membatasi waktu penggunaan perangkat listrik.

4. Monitoring melalui web secara real time nilai suhu dan kelembapan dalam gedung.

5. Monitoring melalui web secara real time nilai penggunaan daya listrik.

6. Monitoring melalui web secara real time jika mendung, hujan gerimis, hujan lebat, dan kondisi terang/panas..

7. Monitoring melalui web secara real time jika ada asap/kebocoran gas.

8. Monitoring melalui web secara real time jika ada api.

9. Monitoring melalui web secara real time jika ada gempa

10. Melihat hasil dari motion detection/mendeteksi dan membunyikan alarm indoor maupun outdoor jika ada orang yang masuk, pada saat setting security activ.

11. Membuka gerbang secara remot atau melalui web sever atau melalui password yang dipasang di dinding.

12. Melihat kondisi dalam gedung maupun luar gedung secara live melalui CCTV.

13. Melakukan teleconfrence dengan cukup menekan tombol pada sistem.

14. Melakukan updating informasi melalui sosial media, seperti twitter dan facebook jika terjadi hal-hal yang tidak diinginkan di dalam rumah.

Sementara itu, berbagai kondisi yang ada juga menuntut pemenuhan kebutuhan non fungsional. Kondisi ini diantaranya adalah ketersediaan jaringan karena rencana pengembangan yang berbasis web. Bentuk antar muka yang digunakan juga diperhitungkan untuk kemudahan pengguna.

Sebelum melakukan pemograman, pertama yang dilakukan adalah perancangan perangkat lunak 
yang akan dibuat. Hasil perancangan perangkat lunak ditampilkan dalam diagram alir (flowchart) berikut ini:

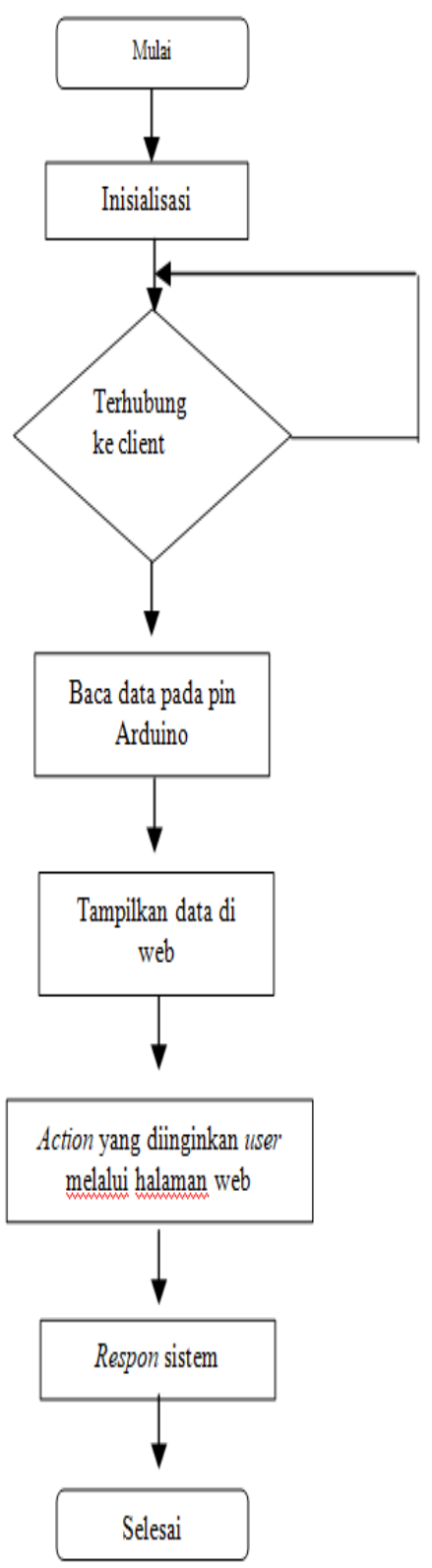

Gambar 5. Diagram Alir Pengiriman dan Pemrosesan Data

\subsection{Perancangan Halaman Web Prototype Smart Building}

Halaman web pada prototype ini dibuat dengan pemogramman HTML javascript, dan CSS yang di embedded (ditanamkan) kedalam Arduino melalui memori card.

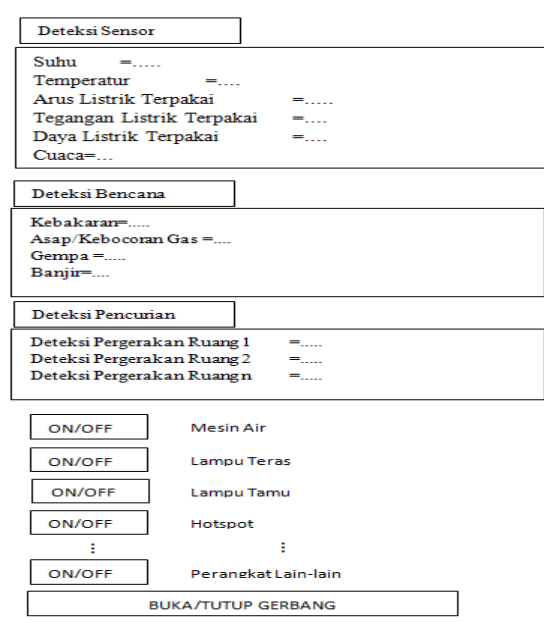

Gambar 6. Halaman Web Prototipe Smart Home

\section{HASIL DAN PEMBAHASAN 4.1 Pengujian Sistem}

Melakukan simulasi dan pengujian sistem melalui komputer maupun smartphone dengan mengambil sampel sampai dengan 10 kali secara berulang dan menguji sistem dengan berbagai perangkat komputer maupun smartphone secara bersama-sama. Pengujian sistem juga dilakuan dengan prangkat komputer jarak jauh atau dengan menggunakan akses jaringan internet.

\subsection{Penulisan Hasil Penelitian}

Membuat analisa hasil pengujian sistem dan memberikan solusi awal dalam perancangan smart building yang nantinya dapat diintegrasikan dengan smart city Ini

\subsection{Hasil Pencapaian}

Dalam bab ini dibahas hasil yang telah dicapai hingga saat ini, serta hambatan yang ditemui selama pengerjaan penelitian. Gambar 6.1 menunjukkan framework yang digunakan pada penelitian

Pada sistem diatas controller arduino berbasis web server mengirimkan informasi yang dibaca pada setiap sensor-sensor dan kemudian mengirimkan informasi dari Ethernet shield yang tertanam pada arduino ke modem dan dilanjutkan ke smartphone yang ditampilkan melalui browser pada saat diminta. Selanjutnya browser tersebut akan mengirimkan perintah dalam bentuk kode html yang kemudian dibuat kondisinya pada bahasa $\mathrm{C}++$ untuk mengartikan perintah yang dimaksud, untuk dilakukan aksi pada mikrokontroller, misalnya menghidupkan atau mematikan relay, dan lain-lain. 


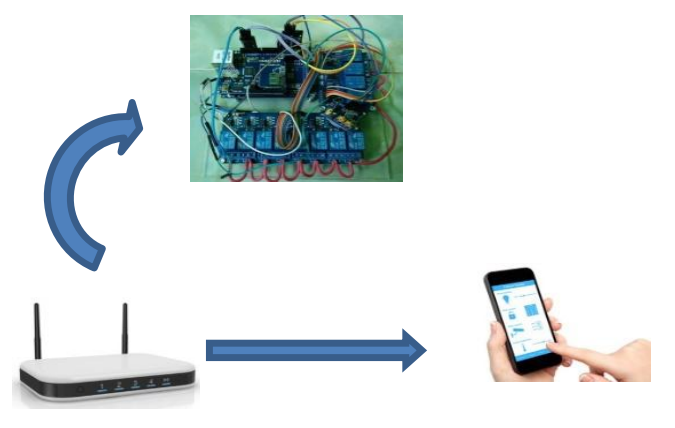

Gambar 7. Framework Sistem Smart Building

Aplikasi web ini diharapkan dapat melakukan monitoring dan kontrol kerja sistem meliputi:

1. Menghidupkan dan memadamkan lampu dari server.

2. Melihat kondisi lampu.

3. Melakukan penjadwalan nyala lampu, dan membatasi waktu penggunaan perangkat listrik.

4. Monitoring melalui web secara real time nilai suhu dan kelembapan dalam gedung.

5. Monitoring melalui web secara real time nilai penggunaan daya listrik.

6. Monitoring melalui web secara real time jika mendung, hujan gerimis, hujan lebat, dan kondisi terang/panas..

7. Monitoring melalui web secara real time jika ada asap/kebocoran gas.

8. Monitoring melalui web secara real time jika ada api.

9. Monitoring melalui web secara real time jika ada gempa

10. Melihat hasil dari motion detection/mendeteksi dan membunyikan alarm indoor maupun outdoor jika ada orang yang masuk, pada saat setting security activ.

11. Membuka gerbang secara remot atau melalui web sever atau melalui password yang dipasang di dinding.

12. Melihat kondisi dalam gedung maupun luar gedung secara live melalui CCTV.

13. Melakukan teleconfrence dengan cukup menekan tombol pada sistem.

14. Melakukan updating informasi melalui sosial media, seperti twitter dan facebook jika terjadi hal-hal yang tidak diinginkan di dalam rumah.

Gambar 8. Aplikasi Smart Building di Android

\section{KESIMPULAN DAN SARAN}

\subsection{Kesimpulan}

Penelitian ini telah dilakukan pada tahapan penyelesaian. Tahapan yang telah dilakukan dari mulai analisis kebutuhan sistem, perancangan sistem sampai dengan implementasi sistem yaitu dihasilkannya suatu prototype smart building berbasis web server yang dapat:

1. Menghidupkan dan memadamkan lampu melalui web browser

2. Melihat kondisi lampu hidup atau mati melalui web browser

3. Monitoring melalui web browser secara kontinu nilai suhu dan kelembapan dalam gedung.

4. Monitoring melalui web browser secara kontinu nilai penggunaan daya listrik.

5. Monitoring melalui web browser secara kontinu jika mendung, hujan gerimis, hujan lebat, dan kondisi terang/panas..

6. Monitoring melalui web browser secara kontinu jika ada asap/kebocoran gas.

7. Monitoring melalui web browser secara kontinu jika ada api.

8. Monitoring melalui web browser secara kontinu jika ada gempa

9. Hasil dari motion detection/mendeteksi dan membunyikan alarm indoor maupun outdoor jika ada orang yang masuk, pada saat setting security activ.

10. Membuka gerbang secara remot atau melalui web sever

11. Melihat kondisi dalam gedung maupun luar gedung seca

12. ra live melalui CCTV.

13. Melakukan teleconfrence dengan cukup menekan tombol pada sistem.

\subsection{Saran}

Luaran dari hasil penelitian ini agar dapat dikembangan lebih lanjut sebagai upaya memberikan gambaran dan temuan suatu prototype dan produk industri dalam rangka turut serta mensukseskan program smart city khususnya di Provinsi Lampung dan di tingkat nasional bahkan internasional pada umumnya. 


\section{DAFTAR PUSTAKA}

[1] Adi, Agung Nugroho. (2012). Mekatronika, Graha Ilmu, Yogyakarta

[2] Arifiyanto, dkk. (2013). Perancangan Prototype Web-Based Online Smart Home Controlled By Smartphon. [Diakses 10 Mei 2016 melalui http://download.

portalgaruda.org/rticle.php?article $=131077 \& \mathrm{val}=$ 4717].

[3] Artanto.

(2012).

MIKROKONTROLER ATMega8535 dan ATMega16. Yogyakarta: ANDI.

[4] Djuandi, Feri. (2011).Pengenalan Arduino.[OnLine].

Tersedia:http://www.TokoBuku.com /arduino-
[5] pengenalan.PDF [diakses pada tanggal 13 Mei 2016]

[6] Kourtit, Karima \& Nijkamp, Peter. (2012). "Smart cities in the innovation age. The

European Journal of Social Science Research", Vol.25, Juni 2012, 93-95. Routledge.

[7] Nam, Taewoo; \& Pardo, Theresa A. (2011). "Conceptualizing Smart City with Dimensions of Technology, People, and Institutions", The Proceedings of the 12th Annual International Conference on Digital Government Research.

[8] Syahbudin. (2014). Analisis Penerapan Smart City dan Internet of Things (IoT) di Indonesia. [Diakses $12 \quad$ Mei 2016 melalui www.academia.edu/15371881/analisis penerapan smart city dan internet of things iot di indonesia]. 


\title{
Template Penulisan Jurnal Expert
}

\author{
First Author ${ }^{\# 1}$, Second Author ${ }^{* 2}$, Third Author ${ }^{\# 3}$ \\ ${ }^{\#}$ First-Third Department, First-Third University \\ Address Including Country Name \\ ${ }^{1}$ first.authorefirst-third.edu \\ ${ }^{3}$ third.authorefirst-third.edu \\ *Second Company \\ Address Including Country Name \\ ${ }^{2}$ second. authoresecond. com
}

\section{Abstrak}

Abstrak dalam bahasa Indonesia ditulis dengan rata kiri-kanan, dengan satu spasi dan satu kolom. Kata "Abstrak" sebagai judul ditulis dalam huruf Times 11-point, tebal, rata tengah, dengan huruf pertama dikapitalkan. Teks abstrak ditulis dengan huruf Times 10-point, satu spasi, sampai lebih kurang 150 kata. Sesudah abstrak tuliskan kata kunci dari makalah tersebut dalam daftar kata kunci. Kemudian dilanjutkan dengan teks utama makalah.

Kata kunci : : kata kunci abstrak

\section{Pendahuluan}

Semua makalah ditulis dalam bahasa Indonesia. Panduan penlisian ini dilengkapi dengan deskripsi huruf, spasi, dan informasi lainnya yang berhubungan dengan penulisan makalah anda. Diharapkan semua penulis dapat mengikuti template yang disediakan dan jika terdapat pertanyaan, silahkan menghubungi editor jurnal EXPERT di journal.expert@ubl.ac.id atau telefon +62721774626 .

\section{Format penulisan}

Materi yang akan dicetak, meliputi teks, gambar ilustrasi, dan grafik harus berada dalam area pencetakan yaitu bidang kertas A4 dengan margin 2.5 $\mathrm{cm}$ di semua sisi kertas. Jangan menuliskan atau meletakkan sesuatu diluar bidang cetak tersebut Seluruh teks ditulis dalam format dua kolom dengan lebar kolom $7.5 \mathrm{~cm}$ dan jarak antar kolom $1 \mathrm{~cm}$, kecuali bagian abstrak yang dituliskan dalam format satu kolom. Seluruh teks harus rata kiri-kanan.

Template ini menggunakan format yang dianjurkan. Untuk mempermudah penulis dalam memformat makalah/jurnalnya, format ini dapat digunakan sebagai petunjuk atau format dasar penulisan.

\section{Judul utama}

Judul utama (pada halaman pertama) harus dituliskan dengan jarak margin $2 \mathrm{~cm}$ dari tepi kertas, rata tengah dan dalam huruf Times 14-point, tebal, dengan huruf kapital pada huruf pertama dari kata benda, kata ganti benda, kata kerja, kata sifat, dan kata keterangan; jangan menggunakan huruf kapital pada kata sandang, kata hubung, terkecuali jika judul dimulai dengan kata-kata tersebut. Sisakan satu 11point baris kosong sesudah judul.

\section{Nama penulis dan afiliasi}

Nama penulis dan afiliasi diletakkan ditengah dibawah judul dan dituliskan dengan huruf Times 11point, tidak tebal. Afiliasi dan email penulis dituliskan dibawahnya dengan huruf Times 10-point, miring. Penulis yang lebih dari satu orang dituliskan dalam dua atau tiga kolom, dengan afiliasi dan email masingmasing.

\section{Tipe huruf}

Huruf yang digunakan adalah turunan dari huruf Times, meliputi Times Roman atau Times New Roman. Jika tipe huruf tersebut didak tersedia pada aplikasi pengolah kata yang digunakan, usahakan untuk memilih huruf yang memiliki kemiripan sedekat mungkin dengan Times. Hindari penggunaan huruf bit-mapped. Diharapkan untuk menggunakan huruf-huruf True-type 1.

\section{Teks utama}

Ketik teks utama dengan menggunakan huruf Times 10-point, satu spasi. Jangan menggunakan dua spasi. Setiap paragraf sebaiknya memiliki panjang lebih kurang $0.5 \mathrm{~cm}$. Pastikan teks ditulis dengan rata kiri-kanan. Jangan menambahkan baris kosong di antara paragraf. Istilah dalam bahasa asing (foreign language) yang tidak dapat diterjemahkan dalam bahasa utama makalah harus dituliskan dalam huruf miring.

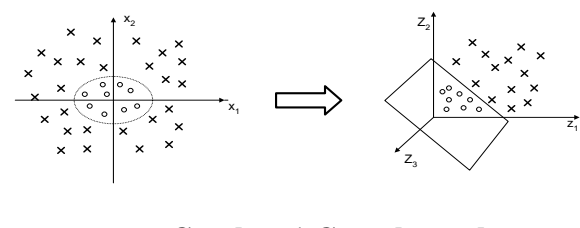

\section{Gambar 1 Contoh gambar}

Keterangan gambar dan tabel dituliskan dengan huruf Times 9-point. Sedangkan pengacuan gambar pada teks menggunakan huruf Times 10-pont. Keterangan gambar diletakkan di bawah, tengah gambar yang dijelaskan. Keterangan tabel diletakkan sebelum tabel dengan rata kiri.

Uraian yang dalam bentuk list (bulleted) dituliskan untuk:

- Uraian yang tidak memiliki aturan pengurutan tertentu

- Uraian yang tidak terikat antara uraian yang satu dan lainnya 


\begin{tabular}{|l|l|l|}
\hline No. & Jumlah & Kecepatan \\
\hline 1. & 25 & $10 \mathrm{~s}$ \\
\hline 2. & 50 & $15 \mathrm{~s}$ \\
\hline
\end{tabular}

Sedangkan untuk uraian yang berurutan dituliskan dengan penanda huruf, untuk:

a. Uraian yang memiliki aturan pengurutan

b. Uraian yang terkait dengan uraian lainnya

c. Uraian yang setiap itemnya akan diacu pada tulisan utama

\section{Judul pertama}

Sebagai contoh, "1. Pendahuluan", dituliskan dalam huruf Times 11-point, tebal, huruf pertama kata pertama ditulis dengan huruf kapital. Gunakan tanda titik (".") sesudah nomor judul.

\subsection{Judul kedua}

Sebagaimana judul pertama, judul kedua dituliskan dengan huruf Times 11-point, tebal. Nomor judul terdiri dari dua angka yang dibatasi dengan tanda titik. Tidak ada titik sesudah nomor judul dengan teks judul.

\subsubsection{Judul ketiga}

Untuk uraian yang lebih panjang dan tidak dapat dituliskan dalam bentuk uraian terurut, digunakan judul ketiga. Judul ketiga menggunakan ukuran huruf yang lebih kecil dari judul pertama dan judul kedua yaitu huruf Times 10-point, tebal. Nomor judul terdiri dari tiga angka yang dibatasi dengan tanda titik. Tidak ada titik sesudah nomor judul dengan teks judul.

\section{Catatan kaki}

Penggunaan catatan kaki dimaksudkan untuk membatu pembaca memperoleh penjelasan terhadap kalimat dalam teks tulisan utama. Catatan kaki dituliskan pada bagian bawah kolom yang memuat acuan ke catatan kaki tersebut. Catatan kaki ditulis dengan huruf Times 8-point, satu spasi. Hindari penggunaan banyak catatan kaki.

\section{Pemrograman}

Listing program dan disain algoritma dituliskan dengan menggunakan huruf dengan lebar yang tetap seperti Courier New 9-point.

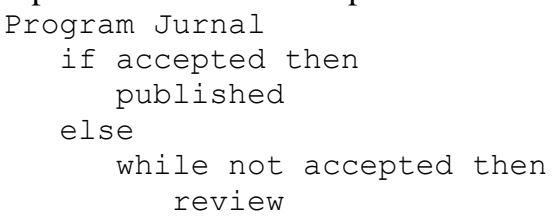

Sedangkan notasi matematika dituliskan dengan menggunakan simbol notasi yang sesuai.

\section{Daftar pustaka}

Daftar pustaka memuat daftar bacaan yang diacu dalam tulisan utama. Daftar pustaka ditulis dengan metode penulisan kepustakaan APA (American Psychological Association) Style, dengan huruf Times 10 -point. Kutipan dalam teks utama yang mengacu kepada daftar pustaka dituliskan dengan angka dalam kurung siku [nama penulis, tahun].

[1] A.B. Smith, C.D. Jones, and E.F. Roberts, Article Title, "Journal", Publisher, Location, Date, Years, pp. 1-10.

[2] Jones, C.D., A.B. Smith, and E.F. Roberts, Book Title, Publisher, Location, Date.

[3] S. Zhang, C. Zhu, J. K. O. Sin, and P. K. T. Mok, "A novel ultrathin elevated channel lowtemperature poly-Si TFT," IEEE Electron Device Lett., vol. 20, pp. 569-571, Nov. 2016. 
Redaksi :

Pusat Studi Teknologi Informasi (PSTI). Gedung Business Center Lt 2 J. Zainal Abidin No. 26 Bandar Lampung Telp. 0721 - 774626 9 772088 " 555000

SistemInformasi@ubl.ac.id 